\title{
A LÍNGUA TERENA NA EDUCAÇÃO INFANTIL DA ESCOLA POLO MUNICIPAL INDÍGENA ALEXINA ROSA FIGUEIREDO ALDEIA BURITI - DOIS IRMÃOS DO BURITI/MS
}

\author{
Adiane Quelri Valente França \\ Ana Lucia Gomes da Silva \\ Denise Silva
}

\begin{abstract}
Resumo: O presente trabalho é um recorte do projeto de dissertação de mestrado desenvolvido no Programa de Pós Graduação em Estudos de Linguagens da UFMS e tem por objetivo descrever o ensino da língua terena na educação infantil ofertada na "Escola Polo Municipal Indígena Alexina Rosa Figueiredo" localizada na Aldeia Buriti, no município de Dois Irmãos do Buriti/MS. Existe uma preocupação mundial para ofortalecimento das línguas indígenas, uma vez que a maioria corre risco de extinção. No caso da aldeia Buriti são poucos os falantes sendo preciso buscar estratégias para o fortalecimento da língua. Nesse contexto, o ensino da língua na escola torna-se uma importante ferramenta para a sua manutenção. Para o desenvolvimento do presente trabalho utilizamos a pesquisa bibliográfica e documental sobre as legislações que garantem o ensino da língua indígena na escola, bem como estudos anteriores sobre o tema e também realizamos pesquisa de campo para compreender como ocorre o ensino da língua na educação infantil da aldeia em questão. A pesquisa, ainda em andamento, oferece um panorama da situação da língua indígena na comunidade e reforça a necessidade de uma política linguística para a escola indígena.
\end{abstract}

Palavras-chave: Educação Infantil. Línguas indígenas. Língua Terena. Educação Escolar Indígena.

\section{A educação indígena Terena}

Desde que uma mulher terena está esperando um filho os cuidados começam, as anciãs instruem as mães a tomarem vários cuidados, nesse período para a gravidez ser saudável e tranquila. A alimentação da mãe é modificada, e alimentos mais saudáveis são inseridos nas refeições que são pensadas sempre para a saúde do bebê. E após o nascimento os cuidados não diminuem agora é com a criança e com a dieta da mãe.

Os ensinamentos Terena perpassam principalmente pelo âmbito familiar, e são de responsabilidade do grupo familiar à apresentação de valores étnicos, o respeito mútuo e a solidariedade. Na cultura Terena, a comunidade exerce papel fundamental na transmissão de saberes tradicionais, pois possui sabedoria para ser comunicada e transmitida por seus membros, que contribuem na formação da identidade da criança Terena.

O aprender terena é baseado na oralidade passada pelos mais velhos e na observação da criança nos adultos, cada espaço é explorado de maneira com que a ação e a experiência gerem conhecimentos necessários para a aprendizagem. Nos afazeres de casa, nos preparativos das festas, nos cuidados com as crianças menores e, principalmente, nas brincadeiras, as crianças relacionam, observam, sentem, vivenciam e aprendem. As crianças participam ativamente de todos os eventos festivos que ocorrem na aldeia.

INTERLETRAS, ISSN No 1807-1597. V. 9, Edição número 34. Outubro, 2021/ Março de 2022- p

Dossiê: Educação, infância, diversidade e ensino de língua em contexto complexo. 
Com o processo de escolarização, isso se torna um desafio para a preservação e para a prática cultural, no sentido de que não haja uma ruptura entre o processo educacional tradicional familiar e o escolar, que introduz outras lógicas espaço-temporais. Por conta disso,

O oferecimento de Educação Infantil para as crianças indígenas tem suscitado muitas criticas e um intenso debate entre especialistas, lideranças e povos indígenas. Muitos defendem que a Educação Infantil atenta contra as tradições, mas algumas comunidades indígenas têm reivindicado espaços educativos para suas crianças pequenas. (TONETO, 2007, p.34)

Segundo as Diretrizes Curriculares Nacionais para a Educação Escolar Indígena na Educação Básica (BRASIL, 2012a), a oferta da Educação Infantil Indígena pode ser uma opção de cada comunidade. Essa opção deverá ser realizada mediante consulta prévia. Havendo demanda e realizada a opção pela Educação Infantil Indígena, os espaços formais/escolares devem considerar, em seus currículos e propostas pedagógicas, as línguas, os conteúdos culturais próprios, a organização do calendário escolar, entre outros aspectos específicos relacionados às dinâmicas culturais das crianças. Propostas que encontrem coerência na construção de uma pedagogia indígena intercultural, que concilie de forma equilibrada a instituição escola para educação infantil, articulando as experiências e os conhecimentos da comunidade com os conhecimentos científicos, que, por sua vez, promovam a melhoria da qualidade de ensino e da educação escolar das crianças indígenas enquanto cidadãos brasileiros.

\section{A educação escolar Indígena e o fortalecimento da língua terena através da educação escolar.}

A Aldeia Buriti possui duas escolas, uma que atende o Ensino Fundamental "Escola Polo Municipal Indígena Alexina Rosa Figueiredo", que funciona no período matutino e vespertino. E uma escola que atende o Ensino Médio e EJA (Educação de Jovens e adultos) "Escola Estadual Natividade Alcântara Marques", que funciona no período Noturno.

A Aldeia Buriti não possui centro de Educação Infantil ou creche, mas tem na Escola Alexina a Educação Infantil que atende alunos de 4 e 5 anos, mas ainda não possui todo o espaço adaptado para atender essa faixa etária, mas atende toda a demanda da comunidade, quando se faz necessário é aberto sala B para atender a demanda.

Desde que se criou a Escola Polo Municipal Indígena Alexina Rosa Figueiredo na Aldeia Buriti, os professores juntamente com lideranças e a comunidade vem se pensando como usar essa ferramenta para ajudar no fortalecimento da cultura e principalmente na revitalização da Língua Materna Terena, uma vez que a educação escolar indígena diferenciada é garantida aos povos indígenas pela Constituição de 1988 e pela Lei de Diretrizes e Bases da Educação Nacional, LDB 9.394/96..

INTERLETRAS, ISSN $N^{o}$ 1807-1597. V. 9, Edição número 34. Outubro, 2021/ Março de 2022- p

Dossiê: Educação, infância, diversidade e ensino de língua em contexto complexo. 
Desde o início de seu funcionamento no ano 2000 até o ano de 2006 a escola Alexina não oferecia o ensino para a Educação Infantil, foi quando Professores, lideranças e comunidade perceberam que se fazia necessário a educação infantil na Escola Alexina. $\mathrm{O}$ oferecimento da Educação Infantil aos povos indígenas é opcional, cabendo a cada comunidade indígena decidir sobre seu oferecimento (BRASIL, 2009; 2012). Como segue:

\begin{abstract}
Art. $8^{\circ}$ A Educação Infantil, etapa educativa e de cuidados, é um direito dos povos indígenas que deve ser garantido e realizado com o compromisso de qualidade sociocultural e de respeito aos preceitos da educação diferenciada e específica.

$\S 1^{\circ}$ A Educação Infantil pode ser também uma opção de cada comunidade indígena que tem a prerrogativa de, ao avaliar suas funções e objetivos a partir de suas referências culturais, decidir sobre a implantação ou não da mesma, bem como sobre a idade de matrícula de suas crianças na escola. (BRASIL, 2012).
\end{abstract}

O direito a uma Educação Escolar Indígena - caracterizada pela afirmação das identidades étnicas, pela recuperação das memórias históricas, pela valorização das línguas e conhecimentos dos povos indígenas e pela revitalizada associação entre escola/sociedade/ identidade, em conformidade aos projetos societários definidos autonomamente por cada povo indígena - foi uma conquista das lutas empreendidas pelos povos indígenas e seus aliados, e um importante passo em direção da democratização das relações sociais no país. (HENRIQUES et al., 2007, p. 9).

No ano de 2006 iniciou o ensino da Educação Infantil na escola Alexina, tendo como Professora da sala da pré-escola I que atende alunos de 04 anos a professora Reinalda Valente França e a professora da pré-escola II que atende alunos de 05 anos a professora Eva Fernandes Bernado. Assim sendo se iniciou um novo desafio para essas professoras, pois não havia material didático para suporte de ensino a educação Infantil, onde elas buscaram alternativas elaborando seus próprios materiais didáticos. A professora Eva relata que foi muito desafiador como tudo é no começo, mas ela buscou estratégias e alternativas para esse novo desafio, onde foi elaborando os materiais e incluindo atividades que retratasse a realidade dos alunos na comunidade indígena da aldeia Buriti.

Além das aulas da professora Regente também tem as aulas de arte, educação física e língua terena, o professor de arte elabora as atividades voltadas para a cultura, incluindo confecção de colar com sementes da própria aldeia, pintura da cultura Terena, sai a campo para colher o urucum e o jenipapo que são os frutos para produzir a tinta de pintura corporal. O professor de Educação Física além das atividades universais inclui também brincadeiras tradicionais da cultura terena, como o jogo de cinco Maria, que utiliza coquinho de bocaiuva seco para jogar, o jogo paredão que também coquinho de bocaiuva

INTERLETRAS, ISSN $N^{\circ}$ 1807-1597. V. 9, Edição número 34. Outubro, 2021/ Março de 2022- p

Dossiê: Educação, infância, diversidade e ensino de língua em contexto complexo. 
seco para jogar, lança e arco e flecha também são utilizadas nas aulas de educação física.

O professor de Língua Terena relata que no início ele trazia a questão da cultura e a língua juntos, mas hoje ele tem focado mais no ensino da língua, pelo fato de que os alunos não são mais falantes da língua terena assim como maior parte da população da aldeia Buriti, alguns alunos só têm contato com a língua terena na escola. E ele tem feito um trabalho incansável para o fortalecimento da língua terena não só dentro de sala de aula, mas também na comunidade.

O Projeto político pedagógico da escola Alexina começou a ser elaborado pelos próprios professores indígenas, juntamente com lideranças e anciões, desde o ano de 2005, e ainda tem sofrido algumas modificações para atender os anseios não só da comunidade escolar, mas também da comunidade em geral, de termos uma educação escolar indígena de fato. A participação de todos os envolvidos ocorreu através de atividades desenvolvidas pela escola, através de diálogo, da comunicação, da interação, os quais foram fatores relevantes para o intercâmbio de experiência, vivências, integrações entre os envolvidos. E a Ementa curricular para a educação Infantil esta inclusa nesse projeto e com objetivo de promover ainda mais o conhecimento terena e o fortalecimento da Língua Terena.

Comecei as entrevistas pelos professores que já atuaram ou atuam na educação infantil e por professores que aturam na direção e coordenação da escola Alexina. Em entrevista ao professor Alberto França Dias, pedagogo (UFMS) Especialista em Gestão escolar (UFMS). 54 anos, foi Diretor da escola Alexina de 2004 a 2009, quando iniciou a sua gestão ainda não havia a educação infantil na escola Alexina, no ano de 2006 foi que iniciou a discussão sobre a educação infantil a partir dos 4 anos de idade, pois no momento da reunião com lideranças, professores e comunidade foi acordado que naquele momento não era preciso um Centro de Educação Infantil na comunidade da Aldeia Buriti, mas sim que a criança entrasse na escola aos 4 anos, pera ter um contato maior com a língua terena que é disciplina ministrada na escola, uma vez que maior parte da comunidade da aldeia Buriti não é mais falante da língua terena. E já no mesmo ano de 2006 foi implantado a educação infantil n a escola Alexina. Quando se iniciou no primeiro que foi oferecida a educação infantil na escola foram 02 salas uma com alunos de 4 anos que é o Pré-escola I e outra com alunos de 5 anos que é a Pré-escola II. O professor Alberto nunca atuou como professor na Educação Infantil, e ele relata que quando iniciou a educação infantil a escola Alexina não tinha material para essas turmas e foram improvisados pelos próprios professores para o início. "Agora no momento atual vejo que Se faz necessário um centro de educação infantil sim na comunidade da aldeia Buriti, mas no modelo de fortalecimento da cultura e principalmente da língua terena".

Entrevistada Ana Sueli Fermino pedagoga (UFMS) 51 anos atuou na Direção da escola como a primeira diretora da escola Alexina e depois também nos anos de 2017 a 2018. Atuou na coordenação nos anos de 2008 e 2009. Relata que a educação infantil foi implantada na escola Alexina no ano de 2006 no mesmo ano em que o ensino fundamental passou a ser de 9 anos. As discussões sobre a implantação da Educação Infantil sempre foram discutidas entre o corpo docente, lideranças tribais e comunidade. Logo no que se INTERLETRAS, ISSN No 1807-1597. V. 9, Edição número 34. Outubro, 2021/ Março de 2022- p

Dossiê: Educação, infância, diversidade e ensino de língua em contexto complexo. 
iniciou a educação infantil, foi duas salas uma de alunos de 4 anos e outra com alunos de 5 anos.

A escola não foi adaptada para receber a faixa etária de 4 e 5 anos, veio mesas com bancos na altura adequada para esses alunos e anos depois veio carteiras com cedera de altura adequada para essa faixa etária. Até hoje a escola não possui banheiros e bebedouros adequado para essa faixa etária. A professora Ana Sueli Nunca atuou na Educação Infantil. Não acha que é viável a comunidade ter um centro de educação infantil porque a criança vai perder o contato com as pessoas mais velhas da família ou seja os avós que são detentores da cultura e isso seria prejudicial para nossa cultura terena.

Entrevistada Eva Fernade Benardo pedagoga (UEMS) 56 anos atua como professora a 28 anos e trabalhou com o povo Kadiwel durante 08 anos. Quando a escola Alexina iniciou seu processo de escolarização não havia a educação Infantil, era oferecido apenas o ensino da $1^{\circ}$ serie a $8^{\circ}$ série do ensino fundamental. No ano de 2006 foi implantada a educação Infantil na escola Alexina, e foi uma reivindicação feita pelos professores juntamente com lideranças e comunidade. Ela relata que foi professora da primeira turma de alunos de 05 anos da escola Alexina. Não havia materiais de pré-escola na escola para utilizarmos, foi um desafio muito difícil e tive que criar materiais e fui adquirindo livros. Relembra que usava o mimeógrafo para fazer atividades para os alunos. No início não trabalhou a cultura em sala, mas hoje ainda atua na pré-escola e já faz questão de trabalhar a cultura terena dentro de sala, fazendo a conscientização da importância da nossa cultura trabalhando a dança, levar anciões para dentro da sala para falar sobre a história do nosso povo terena e a pintura terena. $\mathrm{O}$ ambiente escolar não é adequado para os alunos nessa faixa etária de 4 e 5 anos desde que começou veio apenas mesas de cadeiras adequadas para essa Faixa etária. Gostaria sim que tivesse o centro de educação infantil na comunidade, mas que fosse para o fortalecimento da cultura terena e principalmente o resgate da língua terena.

Entrevistada Amélia Fermino Fernandes, pedagoga tem 44 anos, atua como professora a 9 anos e está como atual Coordenadora na escola Alexina. E quando se trada da educação infantil na escola Alexina o ambiente não recebeu a devida estrutura para receber alunos de 4 e 5 anos. Penso que é preciso uma sala separada que tenha jogos e brinquedos educativos. Vejo que faz necessário um centro de educação infantil na nossa comunidade, para as crianças já irem se familiarizando com a escola e também pelo fato de alguns pais precisarem trabalhar fora da aldeia e não terem com quem deixar os filhos.

Entrevistada Jodinelsa Rodrigues Ramos, pedagoga (Anhanguera - CG) 27 anos, atua como professora a 3 anos. E no ano de 2021 está atuando na sala da Pré-escola II - B. Vejo que as cadeiras e carteiras são adequadas para o tamanho dos alunos já os banheiros e bebedouros não são adequados para o tamanho deles. Os materiais que utilizo são comprados por mim mesma e também pesquiso na internet, monto jogos e materiais lúdicos para os alunos, pois a escola não possui esses recursos. Trabalho a questão da cultura mostrando artesanatos da nossa cultura e também a pintura terena e também a preservação da natureza que é importante para nós povos indígenas. Vejo que é necessário um centro de educação infantil, porque o aluno já vai se familiarizando com o ambiente INTERLETRAS, ISSN $N^{\circ}$ 1807-1597. V. 9, Edição número 34. Outubro, 2021/ Março de 2022- p

Dossiê: Educação, infância, diversidade e ensino de língua em contexto complexo. 
escolar e quando chegar na pré-escola já vai facilitar para o professor e aluno. E também pela questão de hoje já ter pessoas da comunidade que trabalha fora e precisa de um lugar adequado para deixar seus filhos.

Entrevistado Gil Paulo Barbosa formado em Filosofia e está cursando pedagogia, 31 anos atua como professor a 5 anos e atualmente está dando aula de Língua Terena para a Educação Infantil. Todo conteúdo aplicado é elaborado por ele mesmo, pois não há matérias específicos de língua terena na escola. O professor é falante fluente da língua terena, mas os alunos nenhum é falante e muitas vezes tem o primeiro contato com a língua terena em sala de aula. No início da carreira como professor trazia a cultura e a língua para trabalhar junto, mas hoje tem focado mais na língua pelo fato de os alunos não ser falante da língua. Seria bom sim ter um centro de educação infantil aqui na comunidade, mas para trabalhar a questão da cultura terena e principalmente a língua terena.

\section{CONSIDERAÇÕES FINAIS:}

\section{REFERÊNCIAS}

BRASIL. Parecer CNE/CEB $n^{\circ} 13$, de 10 de maio de 2012. Diretrizes Curriculares Nacionais para a Educação Escolar Indígena. Brasília, DF: MEC, 2012b. Disponível em: http://portal.mec.gov.br/index.php?option=com

docman\&view=download \&alias=10806-pceb013-12-pdf \&Itemid=30192

BRASIL. Ministério da Educação. Resolução CNE/CEB No 5, de 17 de dezembro de 2009. Fixa as Diretrizes Curriculares Nacionais para a Educação Infantil. Brasília, DF: MEC, 2009. Disponível em: http://www.seduc. ro.gov.br/portal/legislacao/RESCNE005_2009.pdf.

BRASIL. Ministério de Educação e do Desporto. Referencial curricular nacional para as escolas indígenas. Brasília, DF: MEC, 1998.

BRASIL. Constituição da República Federativa do Brasil. Brasília/DF: Senado, 1988.

HENRIQUES, R.; GESTEIRA, K.; GRILLO, S; CHAMUSCA, A. (org.). Cadernos SECAD 3: Educação Escolar Indígena: diversidade sociocultural indígena ressignificando a escola. Brasília, DF: Cadernos SECAD/MEC/BRASIL, 2007.

TONETO, B. Educação infantil indígena: o que é melhor para os curumins? Revista Criança, São Paulo, 2007. Disponível em: www.2.ufpl.edu.br/ CIC/2008/cd/pages/pdf/CS/cs-01573.

INTERLETRAS, ISSN $N^{\circ}$ 1807-1597. V. 9, Edição número 34. Outubro, 2021/ Março de 2022- p

Dossiê: Educação, infância, diversidade e ensino de língua em contexto complexo. 
